\title{
US doctors divided over health reforms
}

Published at www.cmaj.ca on Jan. 15

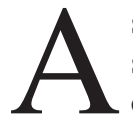
s the United States Congress scrambles to iron the kinks out of its health reform legislation, America's two most influential medical associations remain deeply divided over the merits of changes respectively proposed by the House of Representatives and Senate in late 2009.

The Chicago, Illinois-based American Medical Association (AMA), which represents approximately 250000 physicians, endorses the core of the reform package, while the Chicago-based American College of Surgeons (ACS), opposes it. The ACS, which represents 77000 surgeons and anesthesiologists, is also backed by 19 other surgical associations representing more than 160000 surgeons.

In short, America's doctors are pretty much evenly divided over the proposed reforms, embodied in a pair of bills passed by the two arms of Congress. They are widely divergent on several issues, including the need for a government-run insurance plan, and are now undergoing a process called reconciliation, with an eye toward crafting a single bill that President Barack Obama could sign into law (CMAJ 2009. DOI:10.1503/cmaj.109-3148).

In a letter to members, the ACS indicated that it could not accept such aspects of the legislation as one which establishes an external advisory board to guide physicians working within the \$445-billion Medicare system that funds about $20 \%$ of all health care, primarily for seniors.

The AMA, by contrast, has stood squarely behind the reform proposals, even delivering an influential endorsement that helped the Senate push through its version of a reform bill in December 2009.

"We chose to support the Senate bill because we think we can have more influence if we stay at the negotiating table," explains Dr. Cecil Wilson,

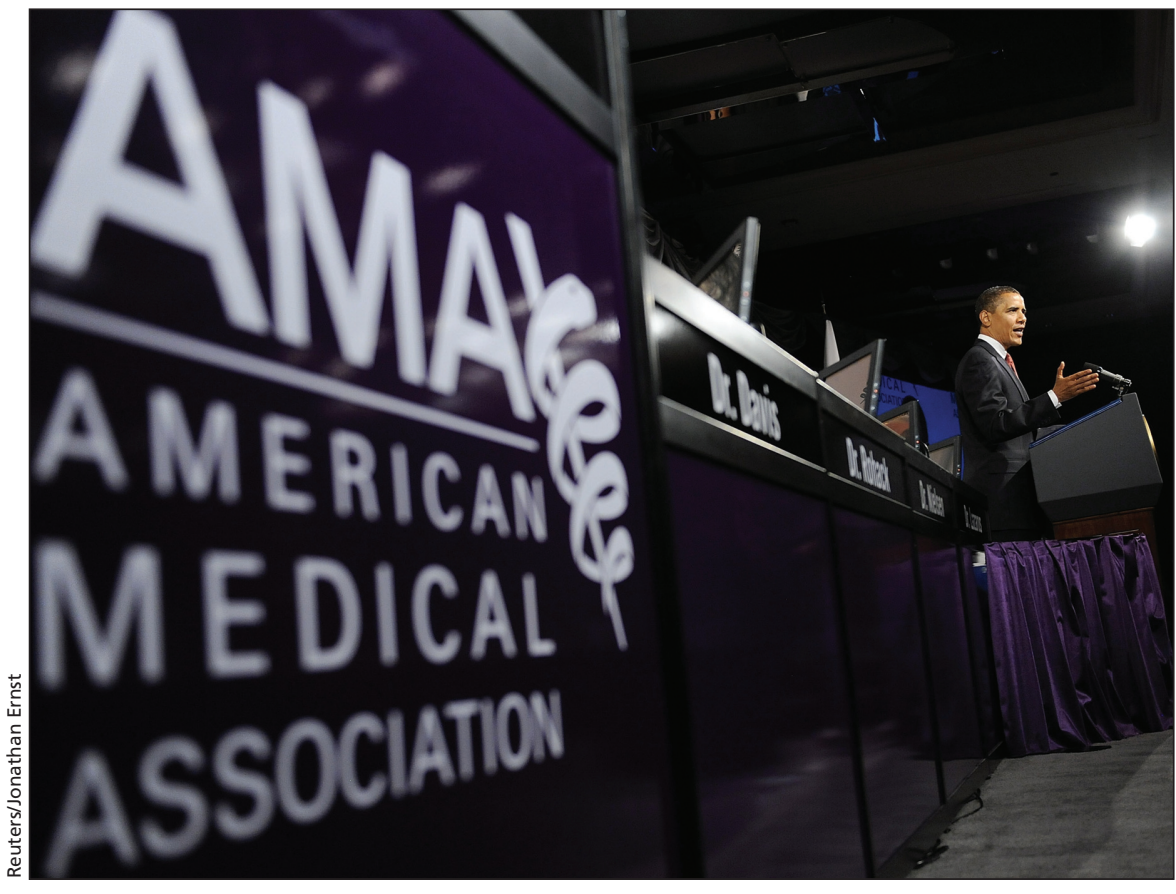

United States President Barack Obama addresses the annual general meeting of the American Medical Association in June 2009.

AMA president-elect. "We are not going to draw lines in the sand publicly until we have to. And that's not going to be until the end. And we're not going to draw lines in the sand on one issue alone."

"The problem with backing away and saying 'no' on individual items is that you lose your place at the table. The groups who have done that are no longer at the table. They will not have input at the joint conference committee."

Because the decision to break ranks with the AMA meant that the ACS would be sidelined in the politicking to influence the final form of the legislation, the move was not taken lightly, says Kristen Hedstrom, ACS assistant director of legislative affairs. "When you oppose a bill, the people you oppose don't necessarily ask your opinion any more."

Hedstrom says the ACS was disappointed that it was only partially successful in its efforts to eliminate provisions that an external advisory board be created to guide Medicare and that rules be introduced making it mandatory for physicians to participate in performance evaluations.

The AMA was able to secure some positive last-minute changes from lawmakers, Hedstrom concedes. "But for our membership - for the surgeon membership — they just didn't go far enough."

The AMA swung its influence behind the Senate bill after the upper arm of Congress scuttled the so-called "public plan option," which would have created a government-run insurance plan. It also takes credit for blocking expansion of Medicare to allow people aged 55-64 to "buy in" to the program and for blocking provisions that would cut Medicare payments to physicians.

But the AMA doesn't flatly oppose the two provisions that triggered the ACS defection.

The first called for the establishment of an Independent Medicare Advisory Board to operate at arm's-length in 
guiding Medicare payments to physicians. Wilson says the AMA is still hoping to temper the effects of that provision by lobbying for change.

The second called for mandatory physician participation - and penalties for doctors who fail to meet performance benchmarks - under the Physician Quality and Reporting Initiative, which now provides bonus payments for physicians who voluntarily participate in quality control programs.

The initiative is "in its infancy but it represents where health care reform is going," says Peter Lee, executive director of national health policy for the San Francisco, California-based Pacific Group on Health. "The fault lines are shifting," he says, noting that AMA has shown real "maturation" on the issue.

Although the AMA opposes mandatory participation and penalties, Wilson is confident legislators will be persuaded to temper their demands. "Our concern is that if you are going to report on what physicians do you need to know their reputations are on the line. The AMA supports the concept of value-based payments, but new payment methodologies must be based on scientific data that is accurate, valid and verifiable. We don't have good guidelines for reporting on surgeons and physicians."

Wilson also warns that AMA support is conditional on substantial changes emerging from the legislative process. "This whole process is still hanging on threads." - Paul Christopher Webster, Toronto, Ont.

DOI:10.1503/cmaj.109-3153 